\title{
Prolonged Activation of Mesolimbic Dopaminergic Neurons by Morphine Withdrawal Following Clonidine: Participation of Imidazoline and Norepinephrine Receptors
}

\author{
François Georges' ${ }^{1,2}$ and Gary Aston-Jones*,1 \\ 'Department of Psychiatry, University of Pennsylvania, Philadelphia, PA, USA
}

\begin{abstract}
The $\alpha 2$ adrenoceptor $(\alpha 2 \mathrm{R})$ agonist clonidine is used as a treatment for heroin addiction. Substantial evidence indicates that dopaminergic and noradrenergic systems have key roles in opiate dependence and withdrawal but the possible interactions between these two pathways remain unclear. The objective of this study was to establish the effects of clonidine pretreatment on ventral tegmental area dopaminergic (VTA DA) neuronal activity during morphine withdrawal. Responses of VTA DA neurons to withdrawal precipitated by naltrexone were characterized in anesthetized rats using extracellular recordings. As expected, withdrawal produced a marked inhibition of VTA DA neuronal activity. However, pretreatment with clonidine prevented this inhibition induced by withdrawal, and instead produced a long-lasting activation of firing rate (+50\%) and burst firing (+19\%). In contrast, pretreatment with a more selective $\alpha 2$ R agonist, UK 14304, did not prevent the inhibition of VTA DA neuron activity during withdrawal. We tested whether the high affinity of clonidine for imidazoline-I receptors (IIRs) was responsible for the difference between these two $\alpha 2 R$ agonists. In morphine-dependent rats pretreated with rilmenidine (mixed $\alpha 2 R / I R$ agonist), precipitation of withdrawal elicited a $22 \%$ increase of VTA DA impulse activity. The action of clonidine on IIRs was studied by coadministering clonidine with RX821002, a specific $\alpha 2 R$ antagonist. Pretreatment with RX821002 plus clonidine prevented the inhibition of VTA DA activity during withdrawal but failed to produce excitation. These results indicate that the pharmacological effects of clonidine on VTA DA neurons during morphine withdrawal is related to actions on IIRs as well as $\alpha 2$ Rs.

Neuropsychopharmacology (2003) 28, | |40-| |49, advance online publication, 2 April 2003; doi: |0. I038/sj.npp. 1300 | 6 |
\end{abstract}

Keywords: dopamine neuronsventral tegmental area; extracellular recording; addiction; imidazoline receptors; rilmenidine

\section{INTRODUCTION}

Opiate addiction is a complex behavioral phenomenon reflecting the effects on several neural systems. Substantial evidence indicates that dopaminergic and noradrenergic systems have key roles in the mechanisms of opiate dependence and withdrawal, and that interactions between them may be important for understanding these roles (Delfs et al, 2000; Laviolette et al, 2002; Maldonado, 1997; Santi and Parker, 2001). However, interactions between the two

\footnotetext{
*Correspondence: Dr G Aston-Jones, Department of Psychiatry, University of Pennsylvania, 705 Stellar Chance/6100, Philadelphia, PA 19104, USA, Tel: +I 215573 5200, Fax: + I 215573 5202, E-mail: gaj@mail.med.upenn.edu

${ }^{2}$ Current address: Centre National de la Recherche Scientifique, Unité Mixte de Recherche 554I 'Interactions Neuronales et Comportements', BP28, Université Victor Segalen, Bordeaux 2, 146 rue Léo Saignat, 33076 Bordeaux cedex, France

Received 12 September 2002; revised 03 January 2003; accepted 06 January 2003

Online publication: 14 January 2003 at http://www.acnp.org/citations/ Npp0 I | 403460
}

pathways remain poorly understood (De Vries and Shippenberg, 2002; Delfs et al, 2000; Gobbi et al, 2001; Harris and Aston-Jones, 1994; Maldonado, 1997). Withdrawal from chronic morphine is associated with opposite changes in noradrenergic and dopaminergic neuronal activities: noradrenergic neurons are activated and noradrenaline release is increased in the cortex and the bed nucleus of the stria terminalis (BNST) (Aghajanian, 1978; Akaoka and AstonJones, 1991; Fuentealba et al, 2000; Rossetti et al, 1993), and conversely ventral tegmental area dopaminergic (VTA DA) neurons are inhibited (Diana et al, 1995; Nowycky et al 1978) and DA release in the nucleus accumbens is consistently reduced (Acquas et al, 1991).

The $\alpha 2$-noradrenergic agonist, clonidine, is currently used as a treatment for opiate addiction (Gold et al, 1980; Gossop, 1988; Gowing et al, 2002). Several animal studies have demonstrated clonidine's ability to lessen somatic signs of opiate withdrawal and attenuate the aversive aspects of this state when administered prior to each withdrawal-conditioning episode (Caillé et al, 1999; Kosten, 1994; Schulteis et al, 1998; Tierney et al, 1988). Clonidine administration also prevents the DA decrease in the nucleus 
accumbens that normally accompanies opiate withdrawal (Pothos et al, 1991). This indicates that interactions between noradrenergic and dopaminergic systems may be involved in clonidine's effects during opiate withdrawal. Indeed, several studies in mice and rats have revealed interactions between ascending noradrenergic and dopaminergic systems (Drouin et al, 2002a, b; Herve et al, 1982; Kawahara et al, 2001; Shi et al, 2000). However, the nature of noradrenaline-dopamine interactions during opiate dependence and withdrawal remains unclear. Therefore, the first aim of this study was to investigate whether pretreatment with clonidine modulates VTA DA neuronal activity during prolonged morphine treatment and withdrawal.

Imidazoline-1 receptors (I1Rs) are pharmacologically and physiologically linked with $\alpha 2$-adrenoreceptors ( $\alpha 2 \mathrm{Rs}$ ) (Bousquet et al, 2000; Bousquet and Feldman, 1999). In the brain, clonidine binds with high affinity to I1Rs (Bricca et al, 1989; Ernsberger et al, 1987). Among other functions, the I1R has been implicated in the hypotensive effect of clonidine and other agents with similar structures (for a review see Bousquet, 2001). In the brain the I1R has a unique distribution, partially overlapping that of $\alpha 2 R$, and is most heavily concentrated in the nucleus tractus solitarius (NTS), BNST, and central amygdaloid nucleus. In contrast, I1Rs are not expressed in the locus coeruleus (LC) (King et al, 1995; Ruggiero et al, 1998). In the central nervous system the functions associated with imidazoline receptors are largely unknown but evidence exists for their involvement in the withdrawal syndrome resulting from chronic opiate abuse (Tierney et al, 1988) as well as in major depression and neurodegenerative diseases (for a review see GarciaSevilla et al, 1999). Therefore, the second aim of the present study was to assess the role of I1Rs in VTA DA neuronal activity during morphine withdrawal. The highly selective $\alpha 2 \mathrm{R}$ antagonist RX821002 was used as a tool to inactivate $\alpha 2 R s$ and unmask the possible effects of clonidine on imidazoline receptors. In this study, we report unique physiological and pharmacological effects of clonidine on VTA DA neurons during morphine withdrawal, related to actions on I1 as well as $\alpha 2$ receptors.

\section{MATERIALS AND METHODS}

\section{Animals}

In all, 78 Sprague-Dawley rats (Taconic Farms Inc.; 200$225 \mathrm{~g}$ ) were used. Rats were housed three or four per cage under controlled conditions $\left(22-23^{\circ} \mathrm{C}, 40 \%\right.$ relative humidity, $12 \mathrm{~h}$ light $/ 12 \mathrm{~h}$ dark illumination cycle; lights on from 07.00 to $19.00 \mathrm{~h}$ ), and were allowed free access to commercial chow and tap water. After an adaptation period, rats were divided into nine groups $(n=4-14$ per group) for electrophysiological experiments.

\section{Induction of Morphine Dependence}

Rats were made morphine dependent by subcutaneous implantation of two morphine pellets, each containing $75 \mathrm{mg}$ of morphine free base (National Institute of Drug Abuse, NIH, Rockville, MD, USA). This procedure has been shown to produce a high degree of dependence on morphine (Gold et al, 1994). The control rats received placebo pellets containing the excipient without morphine $(n=2)$ or were unimplanted $(n=12)$. The implantation was performed under deep halothane anesthesia. Electrophysiological experiments were performed between 4 and 6 days following the implantation of morphine pellets.

\section{Surgery}

For surgical procedures, animals were anesthetized with $3 \%$ halothane in air administered through a face mask. A tracheotomy was performed and $2 \%$ halothane was delivered through a tracheal cannula via spontaneous respiration for surgical procedures. Animals were placed in a stereotaxic frame and body temperature was maintained at $36-38^{\circ} \mathrm{C}$ using a thermistor-controlled electric heating pad. All incision points were infiltrated with a longlasting anesthetic (sensorcaine $0.5 \%$ ). The skull was exposed, and a hole was drilled above the VTA $(5.3 \mathrm{~mm}$ caudal to bregma; $0.8 \mathrm{~mm}$ lateral to the midline).

\section{Drugs}

The jugular vein was cannulated for intravenous (i.v.) administration of pharmacological agents. The DA receptor agonist apomorphine hydrochloride $(0.1 \mathrm{mg} / \mathrm{kg}$; Sigma, St Louis, MO, USA) and the D2 DA receptor antagonist eticlopride $(0.1 \mathrm{mg} / \mathrm{kg}$; Sigma, St Louis, MO, USA) were prepared in $0.9 \%$ sterile $\mathrm{NaCl}$ and were used to characterize pharmacologically VTA DA neurons. Naltrexone hydrochloride (Tocris, Ellisville, MO, USA), clonidine (Sigma, St Louis, MO, USA), rilmenidine (Sigma, St Louis, MO, USA), and RX821002 hydrochloride (Tocris, Ellisville, MO, USA) were dissolved in $0.9 \%$ sterile $\mathrm{NaCl}$. UK14304 (Tocris, Ballwin, MO, USA) was dissolved at $100 \mathrm{mM}$ in dimethyl sulfoxide (DMSO) and diluted in $0.9 \%$ sterile $\mathrm{NaCl}$. Naltrexone hydrochloride $(0.1 \mathrm{mg} / \mathrm{kg})$ was given i.v. clonidine $(0.1 \mathrm{mg} / \mathrm{kg})$, UK14304 $(0.1 \mathrm{mg} / \mathrm{kg})$, rilmenidine $(5 \mathrm{mg} /$ $\mathrm{kg}$ ), and RX821002 hydrochloride $(10 \mathrm{mg} / \mathrm{kg}$ ) were given intraperitoneally (i.p.).

\section{Ventral Tegmental Area Recordings}

During recording experiments, the concentration of halothane was kept at 1.0 to $1.2 \%$. A glass micropipette (tip diameter $=2-3 \mu \mathrm{m}, 4-6 \mathrm{M} \Omega$ ), filled with a $2 \%$ pontamine sky blue solution in $0.5 \mathrm{M}$ sodium acetate, was lowered into the VTA. DA neurons were identified according to wellestablished electrophysiological features (Georges and Aston-Jones, 2002; Grace and Bunney, 1983; Grace and Bunney, 1984; Guyenet and Aghajanian, 1978; Tepper et al, 1984). These included: (1) action potential with biphasic or triphasic waveform more than $2.5 \mathrm{~ms}$ in duration; (2) slow spontaneous firing rate (2-9 impulses/s); (3) single and burst spontaneous firing patterns (characterized by spikeamplitude decrement); and (4) inhibition of spontaneous activity by DA receptor agonists and subsequent reversal by DA receptor antagonists. Signals were amplified and filtered $(0.1-5 \mathrm{kHz}$ bandpass) using conventional electronics. Spikes of single neurons were discriminated and digital pulses were led to a computer for on-line data collection using a laboratory interface and software (CED 1401, SPIKE 2; 
Cambridge Electronic Design). Only one cell was studied in each rat.

\section{LC Recordings}

To confirm that adrenergic drugs used in this study were effective in the CNS, we evaluated their ability to modulate the LC neuronal activity in a separate group of drug-naive rats. A hole was drilled in the skull above LC $(3.7 \mathrm{~mm}$ caudal to lambda and $1.2 \mathrm{~mm}$ lateral to midline), and the dura was reflected. Extracellular recordings from individual neurons were obtained with glass micropipettes (tip diameter $=2$ $3 \mu \mathrm{m}, 4-6 \mathrm{Mohm})$ filled with a $2 \%$ pontamine sky blue solution in $0.5 \mathrm{M}$ sodium acetate. LC neurons were tentatively identified at the time of recording on the basis of characteristic impulse waveforms and spontaneous and evoked discharge patterns as previously reported (Aghajanian et al, 1977; Ennis and Aston-Jones, 1988). Recordings were processed by standard electrophysiological methods as described above.

\section{Histology}

At the end of each recording penetration the electrode placement was marked with an iontophoretic deposit of pontamine sky blue dye $(-20 \mu \mathrm{A}$, continuous current for $12-15 \mathrm{~min})$. After the experimental procedures, the animals were deeply anesthetized with halothane (5\%) and decapitated. Brains were removed and snap-frozen in a solution of isopentane at $-70^{\circ} \mathrm{C}$.

\section{Data Analysis}

Three parameters of VTA impulse activity were computed over $200 \mathrm{~s}$ epochs before and after drug administration: the basal firing rate, the proportion of spikes that occurred in bursts and the regularity of firing. The onset of a burst was defined as the occurrence of two spikes with an interspike interval $<80 \mathrm{~ms}$ (Grace and Bunney, 1983). The percentage of spikes in bursts (SIB) was calculated by dividing the number of spikes occurring in bursts by the total number of spikes occurring in the same period of time. Variations of burst firing are reported throughout this study as the percentage of SIB postdrug minus the percentage of SIB predrug. Regularity of firing was measured from the variation coefficient, that is, the standard deviation/mean value of interspike intervals (Grenhoff and Svensson, 1993). Results are expressed throughout as means \pm SEM. When two means were compared, statistical significance of their difference was assessed using two-tailed paired Student's $t$ tests. For multiple comparisons, values were subjected to a one-way analysis of variance (ANOVA) followed by post hoc Dunnett or Newman-Keuls tests.

\section{RESULTS}

Data are reported for 68 histologically verified VTA neurons, which were identified as dopaminergic according to well-established electrophysiological features (see Materials and Methods). Spontaneously discharging nonburstand burst-firing DA cells (Grace and Bunney, 1984) typically fired in a slow, irregular pattern at an average rate of $4.34 \pm 0.42 \mathrm{~Hz}$ for the nondependent rats $(n=14)$ and $5.91 \pm 0.30 \mathrm{~Hz}$ for the dependent rats $(n=54)$ $(p<0.001$, Student's $t$-test). Action potentials of VTA DA neurons in drug-naive and morphine-dependent rats had biphasic or triphasic waveforms with an average duration of $3.02 \pm 0.05 \mathrm{~ms}$. The DA receptor agonist apomorphine was administered for the last DA neuron recorded in each experiment $(0.1 \mathrm{mg} / \mathrm{kg}$ i.v.; $n=15)$. As previously reported (Grace and Bunney, 1983, 1984), this drug consistently inhibited spontaneous impulse activity of DA neurons within $30 \mathrm{~s}$ of injection. A subsequent injection of the D2 DA receptor antagonist eticlopride $(0.1 \mathrm{mg} / \mathrm{kg}$ i.v.) consistently restored impulse activity (characteristic response is shown in Figure 3d).

\section{Clonidine Pretreatment Induces a Lasting Increase of VTA Dopamine Neuronal Activity During Morphine Withdrawal}

Administration of naltrexone $(0.1 \mathrm{mg} / \mathrm{kg}$ i.v. $)$ to morphinedependent rats reduced the impulse activity of VTA DA neurons to about $75 \%$ of the predrug baseline within $5 \mathrm{~min}$ (rate before naltrexone: $6.6 \pm 1.0 \mathrm{~Hz}$, rate after naltrexone: $4.9 \pm 1.0 \mathrm{~Hz}, p<0.05$, Student's $t$-test, $n=5$; Figures 2 and 3 , typical example in Figure $2 \mathrm{~b}$ ). This reduction persisted several hours and none of the cells showed a return to baseline activity. Naltrexone administered to nondependent rats had no significant effect on the firing rate or burst firing of VTA DA neurons $(n=5)$. i.p. Administration of clonidine to drug-naive rats had no significant effect on the firing rate of VTA DA neurons (7.6\% decrease during 5$10 \mathrm{~min}$ following clonidine injection, $n=9$, Figure 1a), and elicited a small (4.6\%) but significant decrease of their burst firing $p<0.01$ Student's $t$-tests, $n=9$ ). No significant differences were detected between placebo-pelleted $(n=2)$ and nonpelleted control rats $(n=7)$. i.p. Administration of clonidine to morphine-dependent rats had no significant effect on the firing rate or burst firing of VTA DA neurons during 5-10 min following clonidine injection $(n=27)$. This activity remained unchanged up to $30 \mathrm{~min}$ following clonidine injection $(n=3)$.

In contrast to the inhibition described above following naltrexone in dependent rats, i.v. injection of naltrexone in dependent rats pretreated with clonidine powerfully increased the tonic firing rate $(+49.9 \%$, ANOVA, $\mathrm{df}=5$, $\mathrm{F}=10.96, p<0.0001)$, the burst firing $(+18.7 \%$, ANOVA, $\mathrm{df}=5, \mathrm{~F}=7.11, p<0.0001)$, and the irregularity of firing $(+42.2 \%$, ANOVA, $\mathrm{df}=5, \mathrm{~F}=5.02, p<0.001)$ of VTA DA neurons ( $n=14$ neurons; Figures 1 and 5, typical example in Figure $1 b)$. As shown in Figure $2 a$ and $c$, naltrexone injection to morphine-dependent rats pretreated with clonidine produced long-lasting activation (firing rate remained above the baseline up to $60 \mathrm{~min}$ after the naltrexone injection, $n=4)$.

\section{Costimulation of $\alpha 2$-Adrenergic Receptors and I1Rs is Required to Prevent the Inhibition of VTA DA Neurons During Withdrawal}

Clonidine is an agonist at I1Rs in addition to $\alpha 2 \mathrm{Rs}$ (Bricca et al, 1993; De Vos et al, 1994; Ernsberger et al, 1993, 1987; Michel et al, 1989; Wallace et al, 1994). To determine if the 


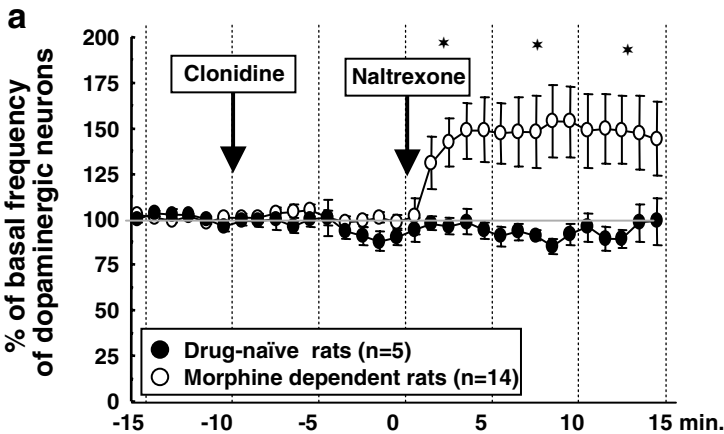

b



Figure I Activation of dopaminergic neurons by morphine withdrawal after clonidine. (a) Effect of naltrexone ( $0.1 \mathrm{mg} / \mathrm{kg}$ i.v.) on VTA DA neuronal impulse activity in morphine-dependent (open symbols) and drug-naive (closed symbol) rats, both pretreated with clonidine $(0.1 \mathrm{mg} / \mathrm{kg}$ i.p.). Data are expressed as a percentage of mean basal levels, and are the mean \pm SEM of 14 morphine-dependent and five drug-naive rats. VTA DA neuron firing rates in morphine-dependent rats are significantly different from baseline at times +2 to +15 min $(* p<0.01$. ANOVA followed by Dunnett's test). VTA DA neuron firing rates in drug-naïve rats are not significantly different from baseline. (b) Oscilloscope traces of impulses from a VTA DA neuron showing the typical firing activity before and after naltrexone injection in a morphine-dependent rat pretreated with clonidine. The naltrexone injection is designated by the line above the trace.

above actions were because of actions at $\alpha 2$ ARs, we studied the effect of UK14304, a specific $\alpha 2$-adrenoreceptor agonist with an I1 binding site/ $\alpha 2$ binding site affinity ratio $<0.01$ (Andorn et al, 1988; Bricca et al, 1993; Buccafusco et al, 1995; Urban et al, 1995). In contrast to the effects observed in morphine-dependent rats pretreated with clonidine, administration of UK14304 (0.1 mg/kg i.v.) prior to naltrexone injection did not prevent the inhibition of VTA DA neuronal activity during withdrawal (Figures 3a and 5, typical example in Figure $3 \mathrm{~b}$ ).

To test whether the interactions of clonidine with morphine withdrawal observed above are because of actions at I1Rs, we carried out additional experiments with rilmenidine, an I1 agonist with a partial affinity for $\alpha 2 \mathrm{Rs}$ (Ernsberger et al, 1997; Schann et al, 2001). In morphinedependent rats pretreated with rilmenidine $(5 \mathrm{mg} / \mathrm{kg}$ i.p.), precipitation of withdrawal with naltrexone elicited a $22.4 \%$ increase of firing rate (ANOVA, $\mathrm{df}=5, \mathrm{~F}=10.96, p<0.0001$, Figure $5 \mathrm{a}$ ), a $9.6 \%$ increase of burst firing (ANOVA, $\mathrm{df}=5$, $\mathrm{F}=7.10, p<0.0001$, Figure $5 \mathrm{~b}$ ), and a $53.6 \%$ increase of the irregularity of firing (ANOVA, $\mathrm{df}=5, \mathrm{~F}=5.02, p<0.001$, Figure 5c) of VTA DA neurons activity during the $15 \mathrm{~min}$ following the naltrexone injection (Figure 3e, typical example in Figure 3f). To confirm that $\alpha 2$ Rs are not the only class of receptors involved in the activation of VTA DA neurons in response to naltrexone injection in morphinedependent rats pretreated with clonidine, the selective $\alpha 2 \mathrm{R}$ antagonist RX821002 (10 mg/kg i.p.) (Hudson et al, 1999; Mallard et al, 1992) was administered $5 \mathrm{~min}$ prior to clonidine pretreatment $(n=9)$. Pretreatment with RX821002 plus clonidine prevented the inhibition of VTA DA neuronal activity (firing rate) during withdrawal, but failed to produce an excitation (Figures $3 c$ and 5, typical example in Figure 3d).

As shown in Figure 4, we confirmed that all adrenergic drugs used in this study were effective in the CNS, as they were able to modulate LC neuronal activity in drug-naive rats. Both clonidine $(0.1 \mathrm{mg} / \mathrm{kg}$ i.p.; $n=2)$ and UK14304 $(0.1 \mathrm{mg} / \mathrm{kg}$ i.p.; $n=3)$ decreased LC neuron firing activity, and pretreatment with RX821002 (10 mg/kg i.p.; $n=5)$ prevented the inhibition of LC activity after clonidine (ANOVA, $\mathrm{df}=3, \mathrm{~F}=3.30, p<0.05$ ).

\section{DISCUSSION}

Our results indicate that clonidine pretreatment causes midbrain DA neurons to become potently activated during opiate withdrawal. This appears to result from actions at both $\alpha 2 R s$ and I1Rs. We propose that clonidine stimulates both $\alpha 2$ Rs and I1Rs, which then interact synergistically in the control of midbrain DA neurons during withdrawal. In the present study, we demonstrate that specific stimulation of $\alpha 2$ Rs with UK14304 did not prevent the inhibition of VTA DA neurons during withdrawal, whereas stimulation of I1Rs alone after pretreatment with clonidine plus the specific $\alpha 2$ AR antagonist RX821002 prevented this inhibition but failed to produce an excitation. A supra-additive effect characterized by a marked activation of VTA DA neuron activity during withdrawal was obtained after clonidine or rilmedinine pretreatment, supporting the possibility that synergy between $\alpha 2$-adrenergic and I1-imidazolinergic mechanisms occurs. In further support of this hypothesis, Bruban et al (2002) recently reported evidence for synergy between $\alpha 2-\mathrm{AR}$ and I1R in the control of the central blood pressure.

\section{Critical Role of I1Rs in the Protective Effect of Clonidine}

The current results indicate a novel role for I1R in preventing the inhibition of VTA DA neurons during morphine withdrawal, and demonstrate that stimulation of $\alpha 2$-ARs alone is not sufficient to prevent this decrease (Figure 5). Such data are in agreement with several behavioral studies showing a high correlation between the affinity of $\alpha 2$-adrenergic agonists at I1Rs and their relative potency for decreasing the physiologic manifestation of the withdrawal syndrome (Buccafusco et al, 1984; Coupar, 1992; Maldonado, 1997; Tierney et al, 1988). In particular, the nonimidazoline agent and full $\alpha 2$-adrenergic agonist UK14304 (Andorn et al, 1988; Jansson et al, 1999) did not affect the expression of major opiate withdrawal signs (body shakes, teeth chattering, or diarrhea), whereas rilmenidine (mixed $\alpha 2 / \mathrm{I} 1$ agonist) blocked the physiologic manifestations of the withdrawal syndrome (Tierney et al, 1988). 
a
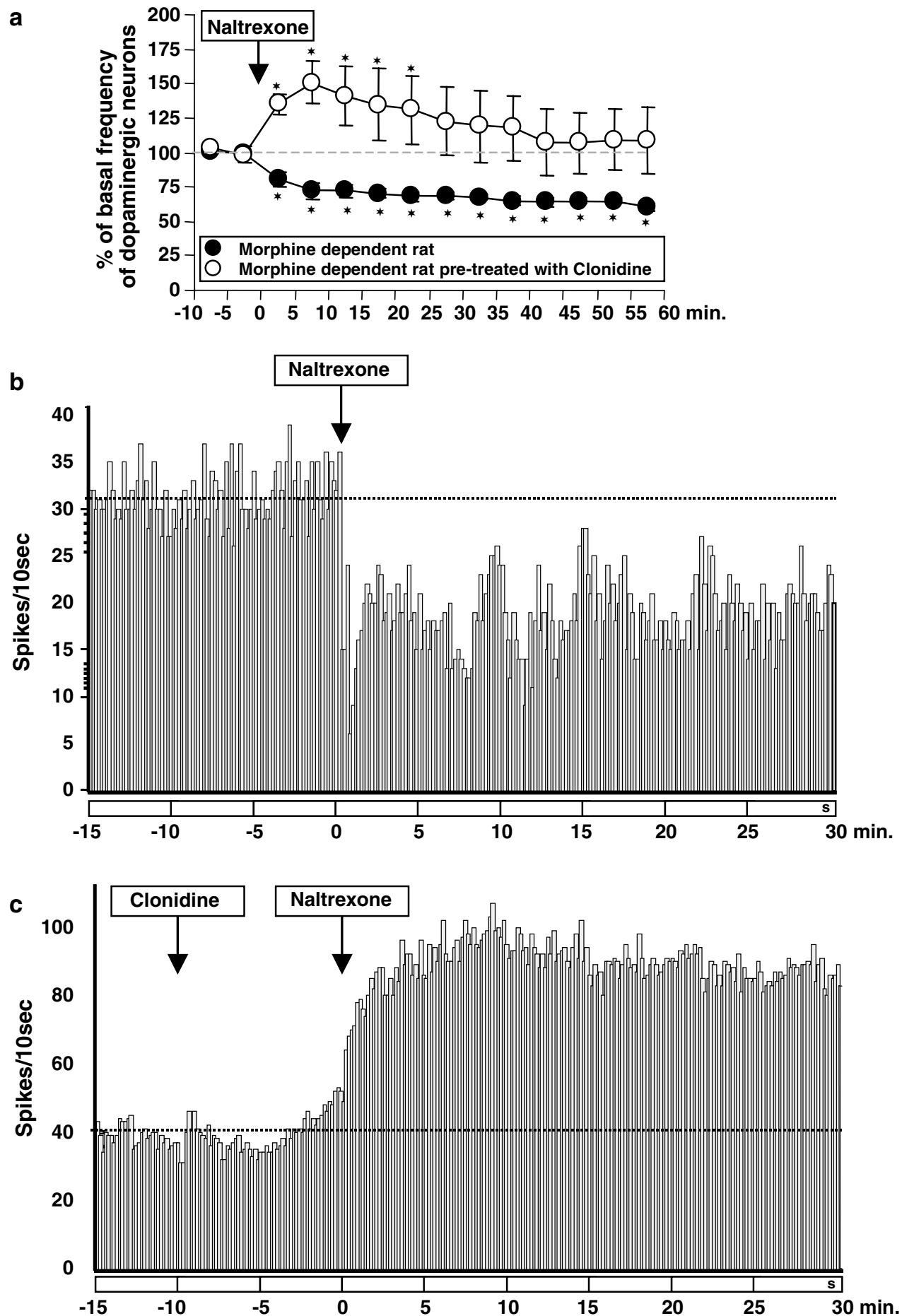

Figure 2 Long-lasting effect of activation of dopaminergic neurons by morphine withdrawal after clonidine. (a) Effect of naltrexone (0.I mg/kg i.v.) on VTA DA neuronal impulse activity in morphine-dependent rats pretreated with clonidine $(0.1 \mathrm{mg} / \mathrm{kg}$ i.p.; open symbols) or without pretreatment (closed symbols). Data are expressed as a percentage of of mean basal levels, and are the mean \pm SEM. Administration of naltrexone $(0.1 \mathrm{mg} / \mathrm{kg}$ i.v.) to morphinedependent rats induced a prolonged reduction of VTA DA impulse activity, and none of the cells returned to baseline activity $(n=5)$; values are significantly different from baseline at all time points following naltrexone (* $p<0.0$ I, ANOVA followed by Dunnett's test). In dependent rats pretreated with clonidine, i.v. injection of naltrexone induced a prolonged increase of the tonic firing rate of VTA DA neurons. Values are significantly different from baseline at times +2.5 to $+22.5 \mathrm{~min}$. (*P $<0.0$ I. ANOVA followed by Dunnett's test). Note that the firing rate remained above the baseline up to 60 min after the naltrexone injection. (b) Firing rate histogram showing the long-lasting inhibition of firing activity in a typical VTA DA neuron after naltrexone injection in a morphine-dependent rat. (c) Firing rate histogram showing the powerful activation of activity in a typical VTA DA neuron after naltrexone injection to a morphine-dependent rat pretreated with clonidine.

The optimal doses and times for pretreatment with noradrenergic drugs in our study were chosen from previous studies demonstrating a clearcut effect on the synthesis of monoamines (Meana et al, 1997) or symptomatology of morphine withdrawal (Coupar, 1992; Tierney et al, 1988). The specific action of clonidine on I1Rs was 


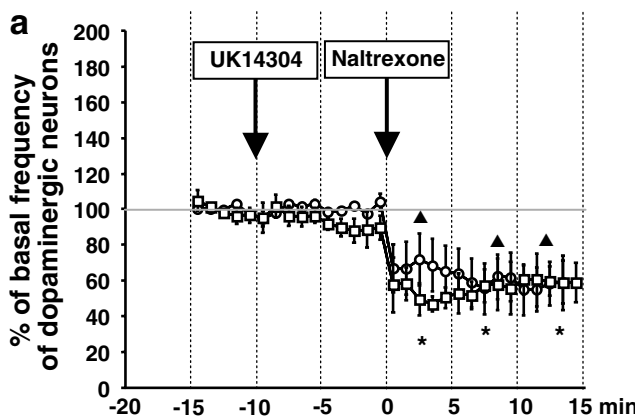

b
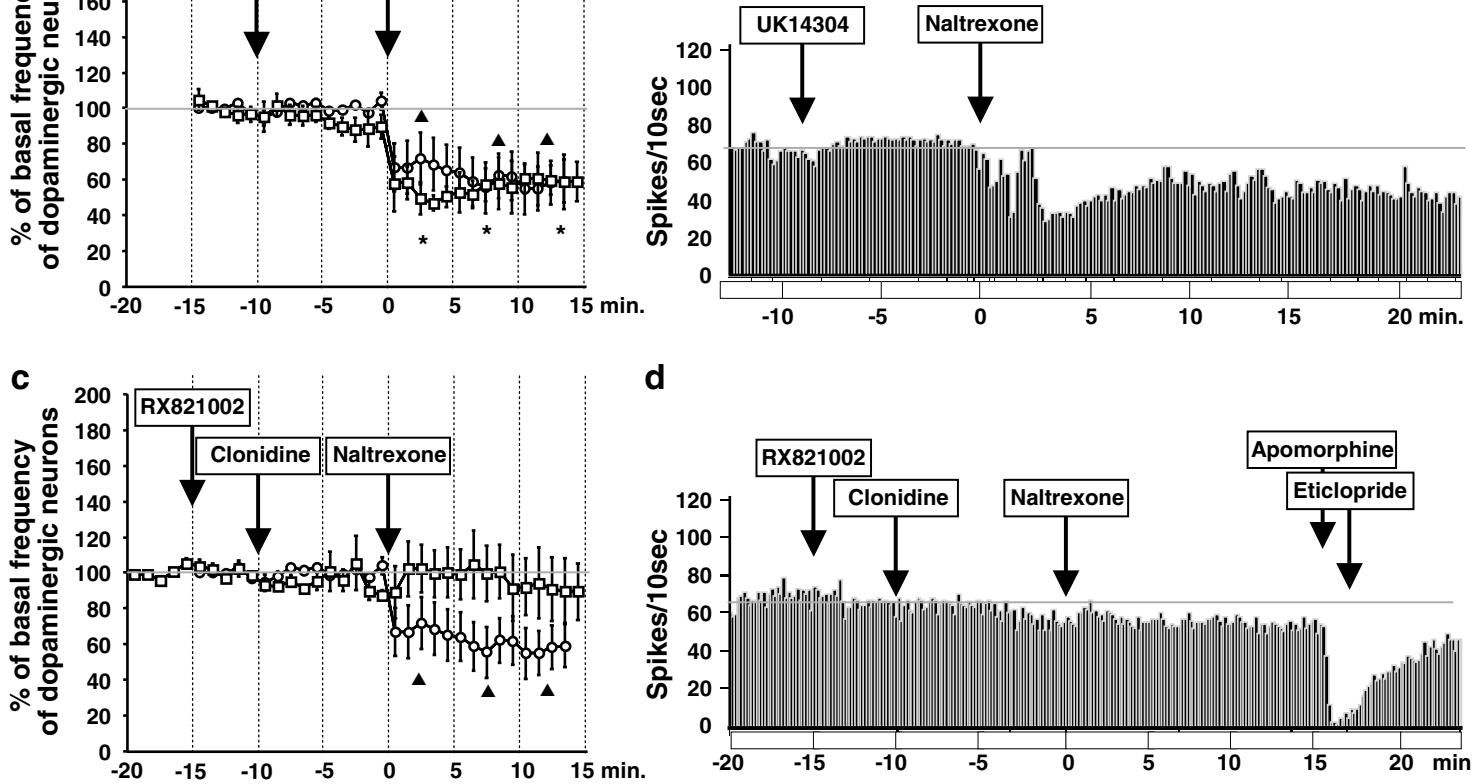

d
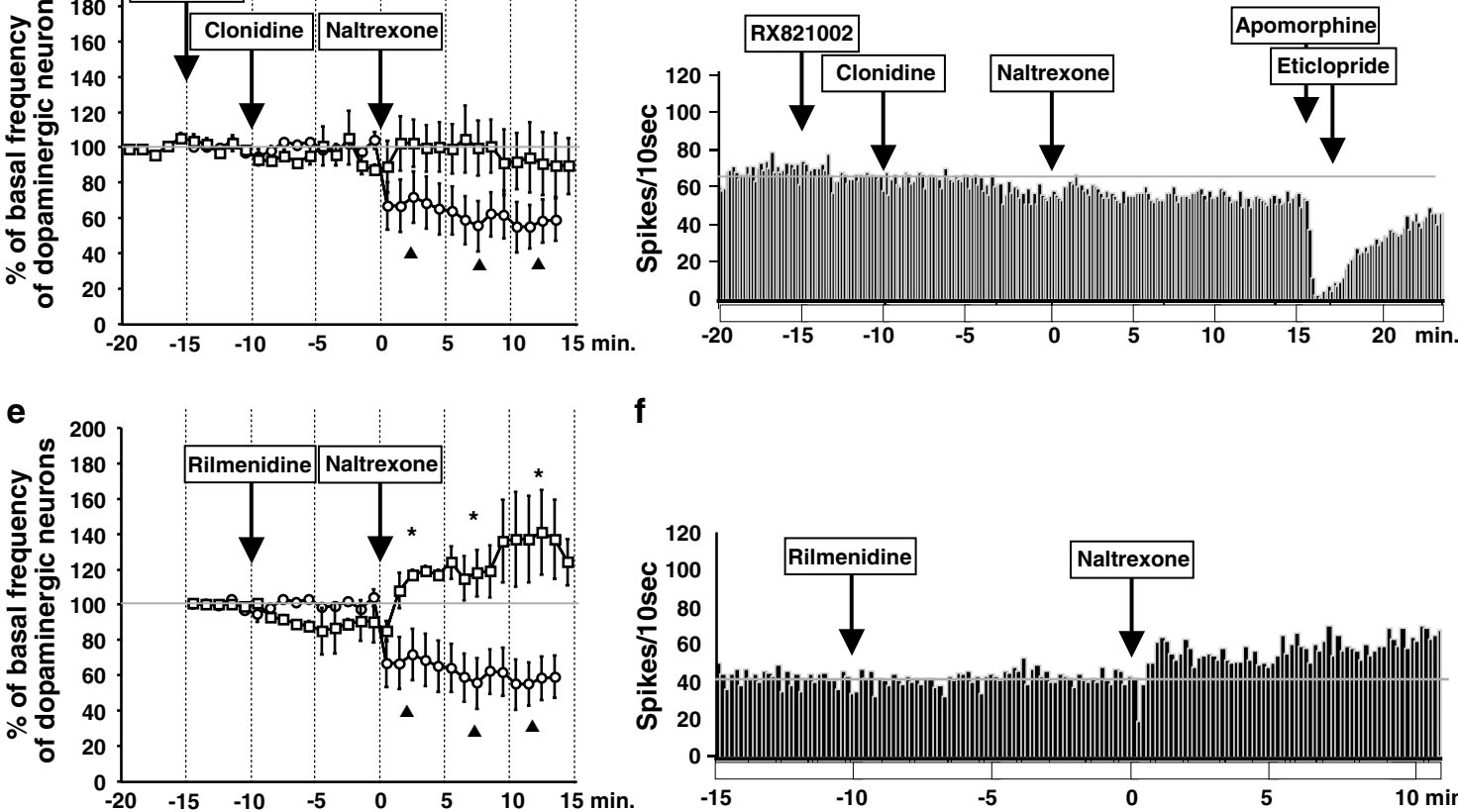

f

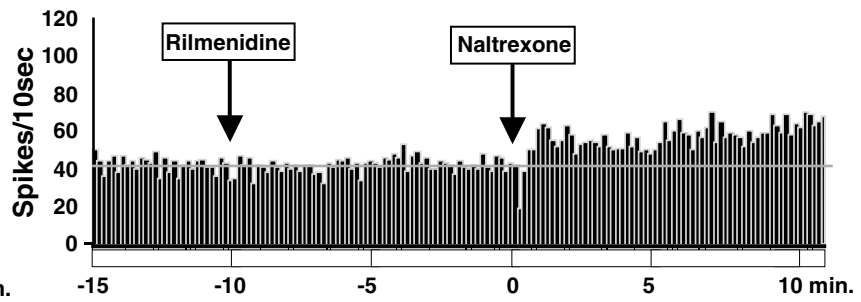

Figure 3 Effect of UK14304, RX821002 plus clonidine, or rilmenidine pretreatment on VTA DA neuron activity before and after precipitation of withdrawal with naltrexone. Data are expressed as a percentage of mean basal levels, and are the mean $\pm \mathrm{SEM}$. (a) Administration of naltrexone (0.I mg/kg, i.v.) to morphine-dependent rats induced a reduction of VTA DA impulse activity ( $n=5$, open circles). Values of this group have been duplicated in panels (c) and (e) (open circles) and are significantly different from baseline at times $+1 \mathrm{~min},+2 \mathrm{~min}$, and $+4 \mathrm{~min}$ to $+15 \mathrm{~min}(\mathbf{\Lambda}<0.01$, ANOVA followed by Dunnett's test). In dependent rats pretreated with UKI 4304 (0.I mg/ $/ \mathrm{kg}$ i.p.), i.v. injection of naltrexone induced a decrease of the tonic firing rate of VTA DA neurons ( $n=5$, open squares). Values are significantly different from baseline at times + I to +15 min $(* p<0.0$ I, ANOVA followed by Dunnett's test). (b) Firing rate histogram showing the inhibition of firing activity in a typical VTA DA neuron after naltrexone injection to a morphine-dependent rat pretreated with UKI 4304. (c) In dependent rats pretreated with RX82 1002 ( $10 \mathrm{mg} / \mathrm{kg}$ i.p.) plus clonidine $(0.1 \mathrm{mg} / \mathrm{kg}$ i.p.), i.v. injection of naltrexone failed to produce a significant decrease of VTA DA tonic firing rate $(n=9$, open squares). (d) Firing rate histograms showing the firing activity in a typical VTA DA neuron after naltrexone injection to a morphine-dependent rat pretreated with $\mathrm{R} \times 821002$ plus clonidine. Note the characteristic inhibition of spontaneous activity by apomorphine $(0.1 \mathrm{mg} / \mathrm{kg}$ i.v) and subsequent reversal by eticlopride $(0.1 \mathrm{mg} / \mathrm{kg}$ i.v). (e) $\mathrm{ln}$ dependent rats pretreated with rilmenidine $(5 \mathrm{mg} / \mathrm{kg}$ i.p.), i.v. injection of naltrexone induced an increase of the tonic firing rate of VTA DA neurons ( $n=8$, open squares). Values are significantly different from baseline at times +1 to +15 min. (*p $<0.05$, ANOVA followed by Dunnett's test). (f) Firing rate histograms showing the activation of firing activity in a typical VTA DA neuron after naltrexone injection to a morphine-dependent rat pretreated with rilmenidine.

studied by coadministering clonidine with RX821002. $\mathrm{RX} 821002$ is a specific $\alpha 2 \mathrm{R}$ antagonist without significant affinity at central imidazoline receptors. It is well known that clonidine inhibits the firing of LC neurons by acting on $\alpha 2$ Rs (Cedarbaum and Aghajanian, 1976). Our recordings of noradrenergic neurons demonstrated that pretreatment with RX821002 prevents the inhibition of LC neurons after clonidine, and confirmed the potent $\alpha 2 \mathrm{R}$ inactivation at central sites as previously reported for this compound (Mallard et al, 1992; Meana et al, 1997; Olmos et al, 1992) (Figure 4). This indirect stimulation of I1Rs was used to address the possible caveat that drugs selective for I1Rs over $\alpha 2$ Rs could lose their selectivity at high doses and stimulate $\alpha 2$ Rs.

Our results indicate that the activation of VTA DA neurons during withdrawal requires stimulation of both $\alpha 2$ Rs and I1Rs simultaneously. Moreover, our results indicate that clonidine is more effective than rilmenidine in activating VTA DA neurons during withdrawal. Considering that the $\alpha 2 / \mathrm{I} 1$ affinity ratio for clonidine is higher than that of rilmenidine (Ernsberger et al, 1997), our results suggest that the intensity of VTA DA activation is most strongly related to the efficacy of $\alpha 2 \mathrm{R}$ stimulation. Further experiments are necessary to determine the mechanism 


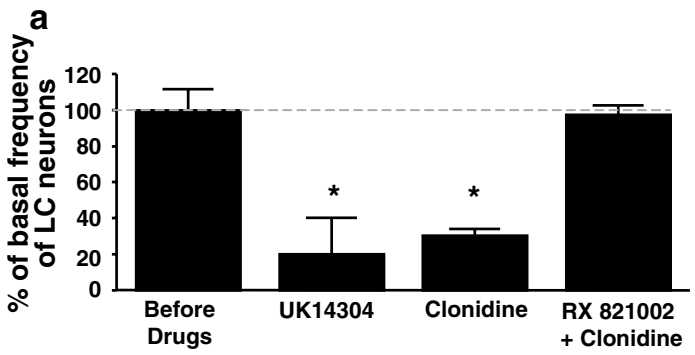

b

C
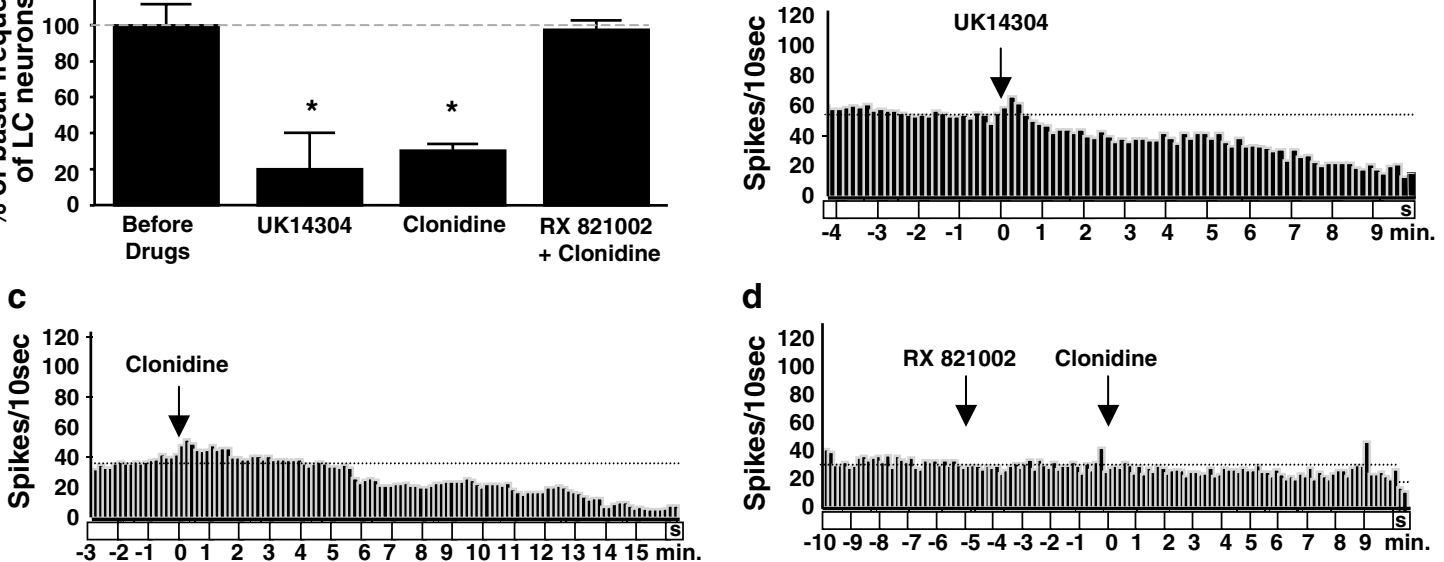

d

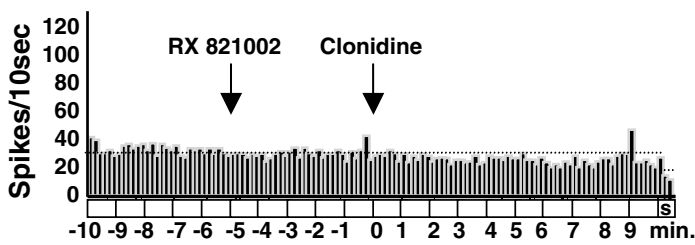

Figure 4 Modulation of LC neuronal activity with adrenergic agents in drug-naive rats. (a) Graph comparing firing rates of LC neurons before and after UKI4304 (0.I mg/kg i.p.), clonidine (0.I mg/ $/ \mathrm{kg}$ i.p.), and RX821002 (I0 mg/kg i.p.) plus clonidine (0.I mg/kg i.p.). Note that both clonidine and UKI4304 decreased LC neuron firing activity and that pretreatment with RX821002 prevents the inhibition of LC neurons after clonidine ${ }^{*} p<0.05$, ANOVA followed by Dunnett's test). (b)-(d) Firing rate histograms showing the modulation of firing activity in three typical LC neurons after UK I 4304, clonidine, and $\mathrm{R} \times 821002$ plus clonidine, respectively.

underlying this requirement for joint $\alpha 2-\mathrm{AR}$ and $\mathrm{I} 1 \mathrm{R}$ activation.

The brain areas where such an interactions occur remain unknown. However, based on the anatomical distribution of I1 and $\alpha 2$-adrenergic receptors (Ruggiero et al, 1998), and the fact that the ventral noradrenergic pathway is involved in the affective response to opiate withdrawal (Delfs et al, 2000), possible candidates include the NTS and the BNST. In fact, Ruggiero et al (1998) report a high expression of the imidazoline receptor protein in the NTS and BNST, especially in axon terminals, suggesting a possible role for these receptors in the regulation of neurotransmitter release. Further experiments examining, for example, the effect of microinjection of clonidine in the different brain regions are needed to establish which of these (or other) structures are the loci of the adrenergic/imidazolinergic interaction. Regardless of the pathway involved, our results show that clonidine acts on $\alpha 2 \mathrm{Rs}$ and I1Rs to trigger a marked and long-lasting activation of VTA DA neurons, which may be part of its clinical efficacy during the treatment of heroin addiction.

\section{Clonidine Modulates the Noradrenaline-Dopamine Interaction During Morphine Withdrawal}

It is noteworthy that clonidine per se does not modify the activity of VTA DA neurons in morphine-dependent rats, but triggers an increase of firing rate of VTA DA neurons, and perhaps more importantly increases bursting and irregularity of firing, during withdrawal (Figure 5b). This is particularly important from a physiologic point of view, because bursts of action potentials are twice as potent as the same number of regularly spaced spikes to trigger dopamine release (Suaud-Chagny et al, 1992). Moreover, our results are consistent with a microdialysis study showing a $20 \%$ increase of DA release in NAC $30 \mathrm{~min}$ after the precipitation of withdrawal in morphine-dependent rats pretreated with clonidine 30 min prior to naloxone administration (Pothos et al, 1991). Our data are also in line with previous behavioral studies demonstrating that clonidine reduced the physical and aversive symptoms of naloxoneprecipitated opiate withdrawal when admistrated prior to the withdrawal episode (Caillé et al, 1999; Kosten, 1994; Schulteis et al, 1998; Tierney et al, 1988).

Our results indicate that i.p. administration of clonidine to drug-naive rats had no significant effect on the firing rate of VTA DA neurons (Figure 1a) and elicited a small decrease of their burst firing. These data contrast with the results of Gobbi et al (2001), which found that clonidine increased VTA DA activity in naive rats. However, these opposing results may be explained by the different routes of administration (i.p. vs i.v.) used for the clonidine in the two studies, and suggest that the dose of clonidine used in our study $(0.1 \mathrm{mg} / \mathrm{kg}$ i.p.) corresponds to the low dose of clonidine $(0.01 \mathrm{mg} / \mathrm{kg}$ i.v.) reported by Gobbi et al (2001) or Grenhoff and Svensson (1989). Moreover, we confirmed the importance of the route of administration in one morphinedependent rat and observed that an i.v. (instead of i.p.) injection of clonidine $(0.1 \mathrm{mg} / \mathrm{kg})$ led to an entirely different result with an increase in VTA DA activity, similar to the results of Gobbi et al (data not shown).

Our data also contrast with the results of Gobbi et al (2001), who found that clonidine had no effect on VTA DA activity during morphine withdrawal. This discrepancy with the present findings may result from differences in techniques used in the two studies, such as the routes of morphine administration (pellet $v s$ injection), the duration of morphine treatment (4-6 days vs 14 days), and the withdrawal method (precipitated $v s$ spontaneous). In addition, the timing of clonidine administration was very different: here, clonidine was given as a pretreatment before precipitated withdrawal, whereas in the Gobbi et al report clonidine was given to rats $24 \mathrm{~h}$ after the last injection of morphine. We used this different timing for clonidine 
administration because the purpose of our study was to investigate the mechanism of the protective effect of clonidine pretreatment previously described in the literature (Caillé et al, 1999; Kosten, 1994; Schulteis et al, 1998; Tierney et al, 1988). To our knowledge, there is no study showing that clonidine injected after the induction of withdrawal is able to reverse the expression of withdrawal. Thus, this difference in the timing of clonidine injection may be critical for the effects produced on VTA DA activity.
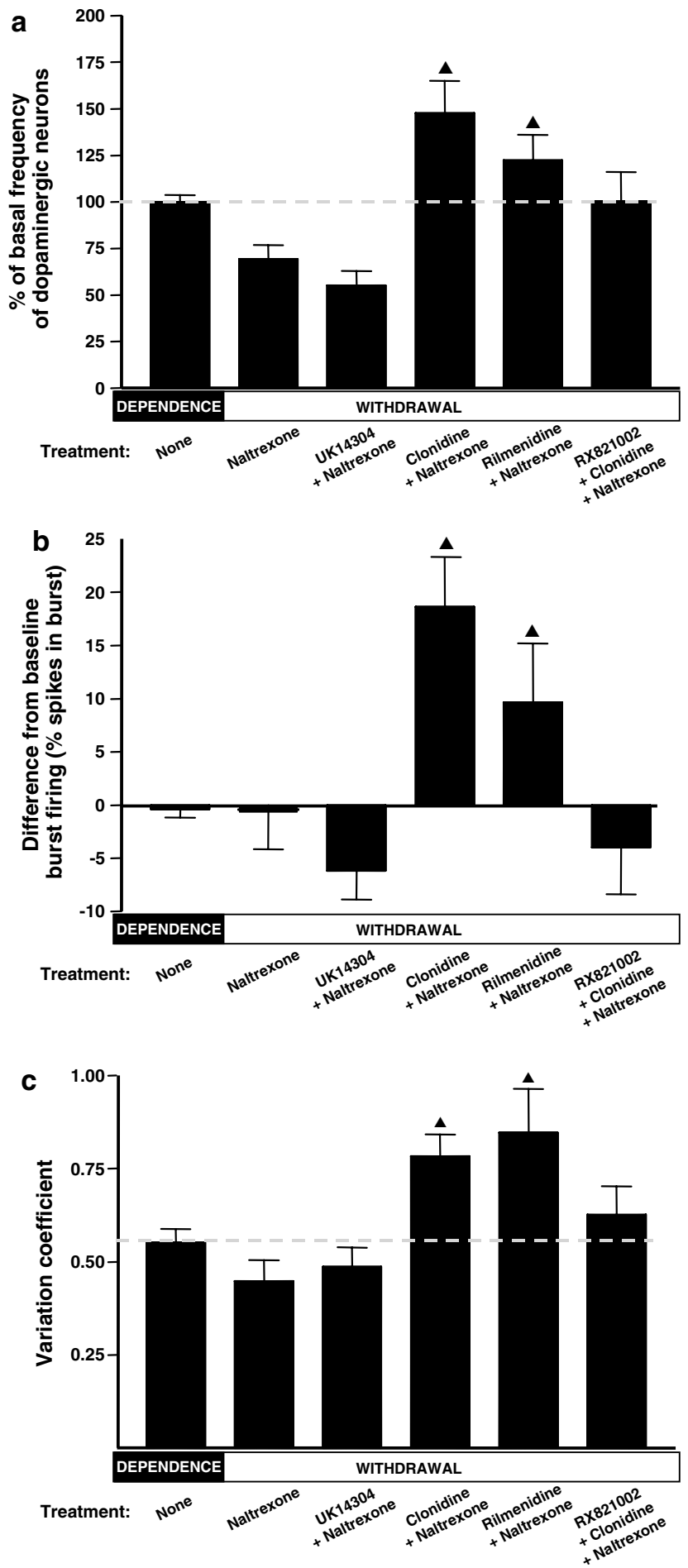

Considering that glutamate afferents control burst firing of dopamine neurons in vivo (Meltzer et al, 1997), it is tempting to propose that glutamatergic neurons innervating the VTA are involved in the clonidine-mediated activation of DA neurons during withdrawal. We recently demonstrated that the ventrolateral subregion of the BNST sends a strong glutamate projection to the VTA (Georges and Aston-Jones, 2002). This area of the BNST contains dense noradrenergic fiber innervation, suggesting a potential noradrenergic regulation of the BNST and subsequent effects on VTA DA neurons. At least certain withdrawal signs involve activation of noradrenergic transmission in the BNST originating in the NTS and A1 (Aston-Jones et al, 1999; Delfs et al, 2000). In addition, an increase of noradrenergic extracellular levels in vBNST in morphinewithdrawn rats has been shown in vivo (Fuentealba et al, 2000). In view of these findings, we propose that clonidine pretreatment may prevent the withdrawal-induced increase of noradrenaline in the BNST, which may disinhibit the glutamatergic BNST projection to the VTA. However, additional experiments are needed to confirm this hypothesis.

\section{Conclusion and Clinical Perspectives}

The ability of clonidine to produce a long-lasting activation of mesolimbic DA neurons following opiate withdrawal is related to its interaction with both $\alpha$ ARs and I1Rs. Current pharmacotherapies, especially methadone and clonidine, have serious side effects, including hypotension, sedation, and their own withdrawal reactions (Gowing et al, 2002). Although clinical implication of our results are somewhat speculative, our findings may provide new insights to help find an alternative pharmacological treatment based on the interaction between $\alpha 2$-adrenoreceptors and imidazoline receptors. Finally, although managed withdrawal or detoxification is not itself a treatment for dependence, it remains a required first step for many forms of long-term treatment (Mattick and Hall, 1996). The mechanisms implicated in the most currently used detoxification clinical protocol (the

Figure 5 Overall effects of i.v. naltrexone $(0.1 \mathrm{mg} / \mathrm{kg})$ following treatment with UKI4304 (0.1 mg/kg i.p., 10 min before naltrexone), clonidine $(0.1 \mathrm{mg} / \mathrm{kg}$ i.p., $10 \mathrm{~min}$ before naltrexone), rilmenidine $(5 \mathrm{mg} / \mathrm{kg}$ i.p., $10 \mathrm{~min}$ before naltrexone), or RX82 1002 ( $10 \mathrm{mg} / \mathrm{kg}$ i.p., $15 \mathrm{~min}$ before naltrexone), or $R \times 821002$ plus clonidine $(0.1 \mathrm{mg} / \mathrm{kg}$ i.p., $10 \mathrm{~min}$ before naltrexone) on VTA DA neuronal firing rate (a), bursting activity (b), or regularity of firing (coefficient of variation, panel (c)) in morphinedependent rats. Note that clonidine or rilmenidine pretreatment increased the firing rate of VTA DA neuron during withdrawal, whereas UKI4304 failed to prevent the characteristic inhibition of firing rate during withdrawal. Similarly, clonidine and rilmenidine pretreatment increased the bursting activity and the coefficient of variation of VTA DA neurons during withdrawal. For firing rates, the scores plotted are the change in rates postdrug as a percentage of predrug rates. For burst-firing analysis, the scores plotted are the percentage of SIB postdrug minus the percentage of SIB predrug. For irregularity of firing, the scores plotted are the coefficients of variation (standard deviation/mean interspike interval) predrug vs postdrug. An increased variation coefficient implies irregularization of firing. ANOVAs followed by Newman-Keuls tests for pairwise comparisons were performed for bursting activity and firing rates. ${ }^{0} p<0.05$ vs VTA DA activity during morphine dependence. 
ultrarapid opiate detoxification procedure, UROD) have not yet been elucidated. The UROD procedure has been designed for heroin or methadone users wishing to detoxify themselves from opiates. Patients are detoxified under general anesthesia using a combination of clonidine and naltrexone (Rabinowitz et al, 1997). This procedure is very consistent with our model of morphine-withdrawn rats, indicating that the activation of the mesolimbic system may contribute to the efficacy of the UROD procedure.

\section{ACKNOWLEDGMENTS}

This work was supported by PHS Grant DA06214

\section{REFERENCES}

Acquas E, Carboni E, Di Chiara G (1991). Profound depression of mesolimbic dopamine release after morphine withdrawal in dependent rats. Eur J Pharmacol 193: 133-134.

Aghajanian GK (1978). Tolerance of locus coeruleus neurones to morphine and suppression of withdrawal response by clonidine. Nature 276: 186-188.

Aghajanian GK, Cedarbaum JM, Wang RY (1977). Evidence for norepinephrine-mediated collateral inhibition of locus coeruleus neurons. Brain Res 136: 570-577.

Akaoka H, Aston-Jones G (1991). Opiate withdrawal-induced hyperactivity of locus coeruleus neurons is substantially mediated by augmented excitatory amino acid input. J Neurosci 11: $3830-3833$.

Andorn AC, Carlson MA, Gilkeson RC (1988). Specific [3H]UK 14,304 binding in human cortex occurs at multiple high affinity states with alpha 2-adrenergic selectivity and differing affinities for GTP. Life Sci 43: 1805-1812.

Aston-Jones G, Delfs JM, Druhan J, Zhu Y (1999). The bed nucleus of the stria terminalis. A target site for noradrenergic actions in opiate withdrawal. Ann NY Acad Sci 877: 486-498.

Bousquet P (2001). I1 receptors, cardiovascular function, and metabolism. Am J Hypertens 14: 317S-321S.

Bousquet P, Bruban V, Schann S, Feldman J (2000). Imidazoline receptors: a challenge. Pharm Acta Helv 74: 205-209.

Bousquet P, Feldman J (1999). Drugs acting on imidazoline receptors: a review of their pharmacology, their use in blood pressure control and their potential interest in cardioprotection. Drugs 58: 799-812.

Bricca G, Dontenwill M, Molines A, Feldman J, Belcourt A, Bousquet P (1989). The imidazoline preferring receptor: binding studies in bovine, rat and human brainstem. Eur J Pharmacol 162: 1-9.

Bricca G, Zhang J, Greney H, Dontenwill M, Stutzmann J, Belcourt A et al (1993). Relevance of the use of [3H]-clonidine to identify imidazoline receptors in the rabbit brainstem. Br J Pharmacol 110: 1537-1543.

Bruban V, Estato V, Schann S, Ehrhardt JD, Monassier L, Renard P et al (2002). Evidence for synergy between alpha(2)-adrenergic and nonadrenergic mechanisms in central blood pressure regulation. Circulation 105: 1116-1121.

Buccafusco JJ, Lapp CA, Westbrooks KL, Ernsberger P. (1995). Role of medullary I1-imidazoline and alpha 2-adrenergic receptors in the antihypertensive responses evoked by central administration of clonidine analogs in conscious spontaneously hypertensive rats. J Pharmacol Exp Ther 273: 1162-1171.

Buccafusco JJ, Marshall DC, Turner RM (1984). A comparison of the inhibitory effects of clonidine and guanfacine on the behavioral and autonomic components of morphine withdrawal in rats. Life Sci 35: 1401-1408.
Caillé S, Espejo EF, Reneric JP, Cador M, Koob GF, Stinus L (1999). Total neurochemical lesion of noradrenergic neurons of the locus ceruleus does not alter either naloxone-precipitated or spontaneous opiate withdrawal nor does it influence ability of clonidine to reverse opiate withdrawal. J Pharmacol Exp Ther 290: 881-892.

Cedarbaum JM, Aghajanian GK (1976). Noradrenergic neurons of the locus coeruleus: inhibition by epinephrine and activation by the alpha-antagonist piperoxane. Brain Res 112: 413-419.

Coupar IM (1992). Effect of alpha 2-adrenoceptor agonists on the expression of morphine-withdrawal in rats. Naunyn Schmiedebergs Arch Pharmacol 345: 553-557.

De Vos H, Bricca G, De Keyser J, De Backer JP, Bousquet P, Vauquelin G (1994). Imidazoline receptors, non-adrenergic idazoxan binding sites and alpha 2-adrenoceptors in the human central nervous system. Neuroscience 59: 589-598.

De Vries TJ, Shippenberg TS (2002). Neural systems underlying opiate addiction. J Neurosci 22: 3321-3325.

Delfs JM, Zhu Y, Druhan JP, Aston-Jones G (2000). Noradrenaline in the ventral forebrain is critical for opiate withdrawal-induced aversion. Nature 403: 430-434.

Diana M, Pistis M, Muntoni A, Gessa G (1995). Profound decrease of mesolimbic dopaminergic neuronal activity in morphine withdrawn rats. J Pharmacol Exp Ther 272: 781-785.

Drouin C, Blanc G, Villegier AS, Glowinski J, Tassin JP (2002a). Critical role of alphal-adrenergic receptors in acute and sensitized locomotor effects of D-amphetamine, cocaine, and GBR 12783: influence of preexposure conditions and pharmacological characteristics. Synapse 43: 51-61.

Drouin C, Darracq L, Trovero F, Blanc G, Glowinski J, Cotecchia S et al (2002b). Alpha1b-adrenergic receptors control locomotor and rewarding effects of psychostimulants and opiates. $J$ Neurosci 22: 2873-2884.

Ennis M, Aston-Jones G (1988). Activation of locus coeruleus from nucleus paragigantocellularis: a new excitatory amino acid pathway in brain. J Neurosci 8: 3644 .

Ernsberger P, Damon TH, Graff LM, Schafer SG, Christen MO (1993). Moxonidine, a centrally acting antihypertensive agent, is a selective ligand for I1-imidazoline sites. J Pharmacol Exp Ther 264: 172-182.

Ernsberger P, Friedman JE, Koletsky RJ (1997). The I1-imidazoline receptor: from binding site to therapeutic target in cardiovascular disease. J Hypertens 15(Suppl): S9-S23.

Ernsberger P, Meeley MP, Mann JJ, Reis DJ (1987). Clonidine binds to imidazole binding sites as well as alpha 2-adrenoceptors in the ventrolateral medulla. Eur J Pharmacol 134: 1-13.

Fuentealba JA, Forray MI, Gysling K (2000). Chronic morphine treatment and withdrawal increase extracellular levels of norepinephrine in the rat bed nucleus of the stria terminalis. $J$ Neurochem 75: 741-748.

Garcia-Sevilla JA, Escriba PV, Guimon J (1999). Imidazoline receptors and human brain disorders. Ann NY Acad Sci 881: 392-409.

Georges F, Aston-Jones G (2002). Activation of ventral tegmental area cells by the bed nucleus of the stria terminalis: a novel excitatory amino acid input to midbrain dopamine neurons. $J$ Neurosci 22: 5173-5187.

Gobbi G, Muntoni AL, Gessa GL, Diana M (2001). Clonidine fails to modify dopaminergic neuronal activity during morphine withdrawal. Psychopharmacology (Berl) 158: 1-6.

Gold MS, Pottash AL, Extein I, Kleber HD (1980). Clonidine and opiate withdrawal [letter]. Lancet 2: 1078-1079.

Gold LH, Stinus L, Inturrisi CE, Koob GF (1994). Prolonged tolerance, dependence and abstinence following subcutaneous morphine pellet implantation in the rat. Eur J Pharmacol 253: 45-51.

Gossop M (1988). Clonidine and the treatment of the opiate withdrawal syndrome. Drug Alcohol Depend 21: 253-259.

Gowing LR, Farrell M, Ali RL, White JM (2002). Alpha2-adrenergic agonists in opioid withdrawal. Addiction 97: 49-58. 
Grace AA, Bunney BS (1983). Intracellular and extracellular electrophysiology of nigral dopaminergic neurons - 1. Identification and characterization. Neuroscience 10: 301-315.

Grace AA, Bunney BS (1984). The control of firing pattern in nigral dopamine neurons: single spike firing. J Neurosci 4: 2866-2876.

Grenhoff J, Svensson TH (1993). Prazosin modulates the firing pattern of dopamine neurons in rat ventral tegmental area. Eur $J$ Pharmacol 233: 79-84.

Guyenet PG, Aghajanian GK (1978). Antidromic identification of dopaminergic and other output neurons of the rat substantia nigra. Brain Res 150: 69-84.

Harris GC, Aston-Jones G (1994). Involvement of D2 dopamine receptors in the nucleus accumbens in the opiate withdrawal syndrome [see comments]. Nature 371: 155-157.

Herve D, Blanc G, Glowinski J, Tassin JP (1982). Reduction of dopamine utilization in the prefrontal cortex but not in the nucleus accumbens after selective destruction of noradrenergic fibers innervating the ventral tegmental area in the rat. Brain Res 237: 510-516.

Hudson AL, Robinson ES, Lalies MD, Tyacke RJ, Jackson HC, Nutt DJ (1999). In vitro and in vivo approaches to the characterization of the alpha2-adrenoceptor. J Auton Pharmacol 19: 311-320.

Jansson CC, Pohjanoksa K, Lang J, Wurster S, Savola JM, Scheinin M (1999). Alpha2-adrenoceptor agonists stimulate high-affinity GTPase activity in a receptor subtype-selective manner. Eur $J$ Pharmacol 374: 137-146.

Kawahara H, Kawahara Y, Westerink BH (2001). The noradrenaline-dopamine interaction in the rat medial prefrontal cortex studied by multi-probe microdialysis. Eur J Pharmacol 418: $177-186$.

King PR, Gundlach AL, Louis WJ (1995). Quantitative autoradiographic localization in rat brain of alpha 2-adrenergic and nonadrenergic I-receptor binding sites labelled by [3H]rilmenidine. Brain Res 675: 264-278.

Kosten TA (1994). Clonidine attenuates conditioned aversion produced by naloxone-precipitated opiate withdrawal. Eur $J$ Pharmacol 254: 59-63.

Laviolette SR, Nader K, van der Kooy D (2002). Motivational state determines the functional role of the mesolimbic dopamine system in the mediation of opiate reward processes. Behav Brain Res 129: 17-29.

Maldonado R (1997). Participation of noradrenergic pathways in the expression of opiate withdrawal: biochemical and pharmacological evidence. Neurosci Biobehav Rev 21: 91-104.

Mallard NJ, Hudson AL, Nutt DJ (1992). Characterization and autoradiographical localization of non-adrenoceptor idazoxan binding sites in the rat brain. Br J Pharmacol 106: 1019-1027.

Mattick RP, Hall W (1996). Are detoxification programmes effective? Lancet 347: 97-100.

Meana JJ, Herrera-Marschitz M, Goiny M, Silveira R (1997). Modulation of catecholamine release by alpha 2-adrenoceptors and I1-imidazoline receptors in rat brain. Brain Res 744: 216-226.

Meltzer LT, Christoffersen CL, Serpa KA (1997). Modulation of dopamine neuronal activity by glutamate receptor subtypes. Neurosci Biobehav Rev 21: 511-518.

Michel MC, Brodde OE, Schnepel B, Behrendt J, Tschada R, Motulsky HJ et al (1989). [3H]idazoxan and some other alpha 2- adrenergic drugs also bind with high affinity to a nonadrenergic site. Mol Pharmacol 35: 324-330.

Nowycky MC, Walters JR, Roth RH (1978). Dopaminergic neurons: effect of acute and chronic morphine administration on single cell activity and transmitter metabolism. J Neural Trans 42: 99-116.

Olmos G, Miralles A, Barturen F, Garcia-Sevilla JA (1992). Characterization of brain imidazoline receptors in normotensive and hypertensive rats: differential regulation by chronic imidazoline drug treatment. J Pharmacol Exp Ther 260: 1000-1007.

Pothos E, Rada P, Mark GP, Hoebel BG (1991). Dopamine microdialysis in the nucleus accumbens during acute and chronic morphine, naloxone-precipitated withdrawal and clonidine treatment. Brain Res 566: 348-350.

Rabinowitz J, Cohen H, Tarrasch R, Kotler M (1997). Compliance to naltrexone treatment after ultra-rapid opiate detoxification: an open label naturalistic study. Drug Alcohol Depend 47: 77-86.

Rossetti ZL, Longu G, Mercuro G, Gessa GL (1993). Extraneuronal noradrenaline in the prefrontal cortex of morphine-dependent rats: tolerance and withdrawal mechanisms. Brain Res 609: 316-320.

Ruggiero DA, Regunathan S, Wang H, Milner TA, Reis DJ (1998). Immunocytochemical localization of an imidazoline receptor protein in the central nervous system. Brain Res 780: 270-293.

Santi AN, Parker LA (2001). The dopamine antagonist, alphaflupenthixol, interferes with naloxone-induced place aversion learning, but not with acute opiate dependence in rats. Pharmacol Biochem Behav 70: 193-197.

Schann S, Bruban V, Pompermayer K, Feldman J, Pfeiffer B, Renard P et al (2001). Synthesis and biological evaluation of pyrrolinic isosteres of rilmenidine. Discovery of cis-/transdicyclopropylmethyl-(4,5-dimethyl-4,5-dihydro-3H-pyrrol-2yl)-a mine (LNP 509), an I1 imidazoline receptor selective ligand with hypotensive activity. J Med Chem 44: 1588-1593.

Schulteis G, Stinus L, Risbrough VB, Koob GF (1998). Clonidine blocks acquisition but not expression of conditioned opiate withdrawal in rats. Neuropsychopharmacology 19: 406-416.

Shi WX, Pun CL, Zhang XX, Jones MD, Bunney BS (2000). Dual effects of D-amphetamine on dopamine neurons mediated by dopamine and nondopamine receptors. J Neurosci 20: 3504-3511. Suaud-Chagny MF, Chergui K, Chouvet G, Gonon F (1992). Relationship between dopamine release in the rat nucleus accumbens and the discharge activity of dopaminergic neurons during local in vivo application of amino acids in the ventral tegmental area. Neuroscience 49: 63-72.

Tepper JM, Young SJ, Groves PM (1984). Autoreceptor-mediated changes in dopaminergic terminal excitability: effects of increases in impulse flow. Brain Res 309: 309-316.

Tierney C, Nadaud D, Koenig-Berard E, Stinus L (1988). Effects of two alpha 2 agonists, rilmenidine and clonidine, on the morphine withdrawal syndrome and their potential addictive properties in rats. Am J Cardiol 61: 35D-38D.

Urban R, Szabo B, Starke K (1995). Involvement of alpha 2adrenoceptors in the cardiovascular effects of moxonidine. Eur J Pharmacol 282: 19-28.

Wallace DR, Muskardin DT, Zahniser NR (1994). Pharmacological characterization of [3H]idazoxan, [3H]RX821002 and p[125I]iodoclonidine binding to alpha 2-adrenoceptors in rat cerebral cortical membranes. Eur J Pharmacol 258: 67-76. 